\title{
Preliminary investigation of the chemo diversity of bioactive molecules produced by endophytic fungi isolated from Manihot utilisima leaf
}

\author{
Ugochukwu Moses Okezie ${ }^{1}{ }^{*}$, Peter Maduabuchi Eze ${ }^{2}$, Festus Basden Chiedu Okoye ${ }^{3}$ and Charles Okechukwu \\ Esimone 1 \\ ${ }^{1}$ Department of Pharmaceutical Microbiology and Biotechnology, Nnamdi Azikiwe, University, Awka, Anambra State, \\ Nigeria. \\ ${ }^{2}$ Department of Environmental Health Science, Faculty of Health Sciences and Technology, Nnamdi Azikiwe University, \\ Awka, Anambra State, Nigeria. \\ ${ }^{3}$ Department of Pharmaceutical and Medicinal Chemistry, Nnamdi Azikiwe University, Awka, Anambra State, Nigeria.
}

GSC Biological and Pharmaceutical Sciences, 2021, 17(01), 011-025

Publication history: Received on 22 August 2021; revised on 26 September 2021; accepted on 28 September 2021

Article DOI: https://doi.org/10.30574/gscbps.2021.17.1.0284

\begin{abstract}
Endophytic fungi have demonstrated a harmless relationship living within the internal tissues of several plant hosts and at the same time produce diverse important bioactive compounds having a wide range of pharmaceutical applicability. In this study, nine endophytic fungi, eight from Cassava leaf: $C l g 1, C l g 2, C \operatorname{lr} 4, C \operatorname{lr} 5, C \operatorname{lr} 6, C \operatorname{lr} 7, C \operatorname{lr} 9$ and one from Cassava mid-rib: CRs3 with distinct cultural features were isolated from healthy leaves of Manihot utilisima and axenic cultures were fermented on sterile rice medium for 21 days. The antimicrobial and antioxidant activities of the fungal crude extracts were evaluated. Chemical analyses of the metabolic profiles of each fungal extract revealed the presence of nine known compounds with established biological activities. Each fungal extract exhibited antimicrobial activities against at least one Gram positive and Gram negative bacteria with an inhibition zone that ranged from $2-6 \mathrm{~mm}$. Clg2 and CRs3 fungal extracts demonstrated moderate potential to scavenge free radical with an inhibition of 58 and $60 \%$ respectively. Septicine, cyclo(prolylvalyl), pentenedioc acid, neurolenin B, rubrofusarin, p-Hydroxybenzoic acid, protocatechuic acid, citreoisocoumarin, palitantin and pestalio pyrone were the compounds detected in the fungal fermentation products. Our findings reveal that M. utilisima leaves harbor endophytic fungi with unique chemodiversity of bioactive secondary metabolites needed for development of new drugs.
\end{abstract}

Keywords: Endophytic fungi; Manihot utilisima, Chemodiversity; Bioactive compounds; Antimicrobial; Antioxidant

\section{Introduction}

Natural products research has continued to show dominance in the search for newer bioactive molecules capable of disrupting the current trend of microbial resistance to available chemotherapeutic agents caused by various pathogenic organisms as well as the harmful effects of free radicals.

Fungal endophytes are a family of fungi that live within internal tissues of living plants without any negative impact on the host plant [1]. Overtime, this group of microbe have proven to be dependable for novel lead molecules with huge chemodiversity of bioactive molecules.

Manihot esculenta Crantz a source of carbohydrates also contains some important phytoconstituents such as flavonoids, saponins, terpenes, glycosides with diverse pharmacological properties including radical scavenging, antimicrobial, antitumor and anti-inflammatory activities [2; 3]. Decoction made from the leaves and stems of M. utilisima are observed

\footnotetext{
${ }^{*}$ Corresponding author: Ugochukwu Moses Okeziea

Department of Pharmaceutical Microbiology and Biotechnology, Nnamdi Azikiwe, University, Awka, Anambra State, Nigeria. 
to possess anti-inflammatory, anticancer, anti-diarrhea and wound healing properties [4]. Also, the crude extract has been reported to have antibacterial as well as antioxidant activities [5; 6]. However, no data have been reported on the chemodiversity of fungal bioactive secondary metabolites of Manihot utilisima, hence this study was embarked upon. In the course of the study, axenic fungal isolates biosynthesized various classes of bioactive molecules that exhibited antioxidant and antimicrobial activities. The aim of the current study was to identify the chemodiversity of secondary metabolites produced by the fungi isolated from healthy leaves of Manihot utilisima.

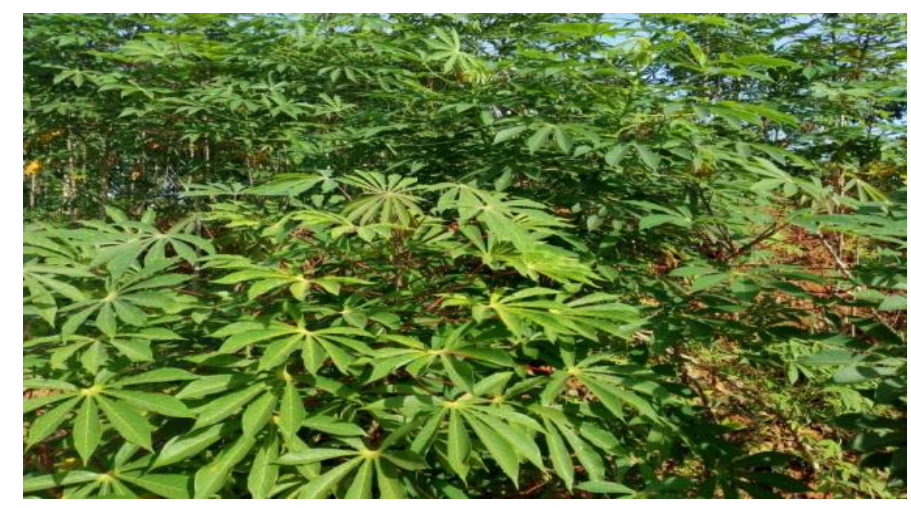

Figure 1 Manihot utilisima

\section{Material and methods}

\subsection{Isolation and purification of endophytic fungi}

Healthy leaves of the plant under study M. utilisima were carefully harvested from a farmland in Agulu, AnambraNigeria. They were transported in a plastic bag immediately to the laboratory. Following washing of the samples under a running tap, samples were further surface-sterilized using 70\% (for $1 \mathrm{~min}$ ), and 2.5\% (3 min) of ethanol and hypochlorite solutions respectively and then rinsed in sterile double distilled water. The edges were re-exposed and cut into approximately $2 \times 1 \mathrm{~mm}$ pieces, and the tissues were aseptically and gently stabbed into the sterile malt extract agar (containing $250 \mathrm{mg} / \mathrm{mL}$ ciprofloxacin) and incubated at $25^{\circ} \mathrm{Cfor} 4-6$ days. Hyphal emerging out of the cultured samples were isolated and multiple sub-culturing were done until axenic cultures were obtained.

\subsection{Fermentation and extraction of fungal metabolites}

Each axenic culture was aseptically transferred into a sterile rice medium and incubated at $25{ }^{\circ} \mathrm{Cfor} 21$ days without shaking. Fungal fermentation products were homogenized using $500 \mathrm{~mL}$ ethylacetate and filtered through a muslin cloth, and the filtrate concentrated at a reduced temperature of $50^{\circ} \mathrm{Cusing}$ a rotary evaporator (R000101564, ST15 OSA, UK).

\subsection{Chemical analysis (Metabolite profiling)}

Retention time and Uv spectra were recorded using a high performance liquid chromatography on a Dionex P580 HPLC system coupled to a photodiode array detector (UVD340S, Dionex Softron GmbH, Germering Germany) and the correlation coefficients were recorded.

\subsection{Bioactivity assay}

\subsubsection{Test organisms}

Antimicrobial activities were carried out using commonly implicated pathogenic organisms which includes Staphylococcus aureus and Bacillus subtilis (as Gram positives); Escherichia coli and Pseudomonas aeruginosa (as Gram negatives) collected from the Department of Pharmaceutical Microbiology and Biotechnology, Faculty of Pharmaceutical Sciences, Nnamdi Azikiwe University, Awka-Nigeria. Cultures were grown on fresh nutrient agar at $37^{\circ} \mathrm{C}$ for 18-24 hr prior to the assay.

\subsubsection{Antibacterial assay}

The potential antimicrobial activities of each of the fungal extract was assessed in vitro against the four pathogenic bacteria [7]. Each fungal crude extract was assayed at a maximum concentration of $1 \mathrm{mg} / \mathrm{mL}$. Briefly, 2 mg of each crude 
fungal extract was reconstituted using $2 \mathrm{~mL}$ Dimethysulfoxide (DMSO). Then, each test organism was standardized to 0.5 MacFarland turbidity standard and inoculated on the surface of the sterile Mueller-hinton agar using a sterile swab stick. A sterile cork borer (diameter $6 \mathrm{~mm}$ ) was used to make hole/well in the agar, and a micropipette was used to transfer $80 \mu \mathrm{l}$ of each fungal extract into their respective wells. The plates were left on the bench and allowed for prediffusion for $15 \mathrm{~min}$ before being incubated at $37^{\circ} \mathrm{Cfor} 18-24 \mathrm{hr}$. After incubation, the potential for antimicrobial activity was observed by measuring using a meter rule, the zone(s) of inhibition produced around the well.

\subsubsection{Antioxidant activity}

The method described by [8] with moderate modifications was adopted. At a concentration of $1 \mathrm{mg} / \mathrm{ml}$, the potential to scavenge free [2,2-diphenyl-1-picryl hydrazyl (DPPH)] radicals were measured at $490 \mathrm{~nm}$ as an index to their antioxidant activity. The reaction mixture included $25 \mu \mathrm{l}$ of the stock, $25 \mu \mathrm{l}$ of DPPH ( $0.1 \mathrm{~mol} / \mathrm{L})$ and $150 \mu \mathrm{l}$ of methanol solution, all in a well. The plates were incubated at $27^{\circ} \mathrm{Cfor} 30 \mathrm{~min}$ and the antioxidant potentials were assessed by measuring the absorbance of the mixtures at $490 \mathrm{~nm}$ using a UV-vis spectrophotometer (721; PEACE SKY, China). An average of three replicates for each extract concentration was done. Antioxidant activities were expressed as the percentage inhibition of each extract and calculated using the formula: [(Ao-A1)/ Ao] * 100; Ao is the absorbance of the blank solution and A1is the absorbance of the positive control

\section{Results}

\subsection{Isolation, purification and bioactivity of endophytic fungi}

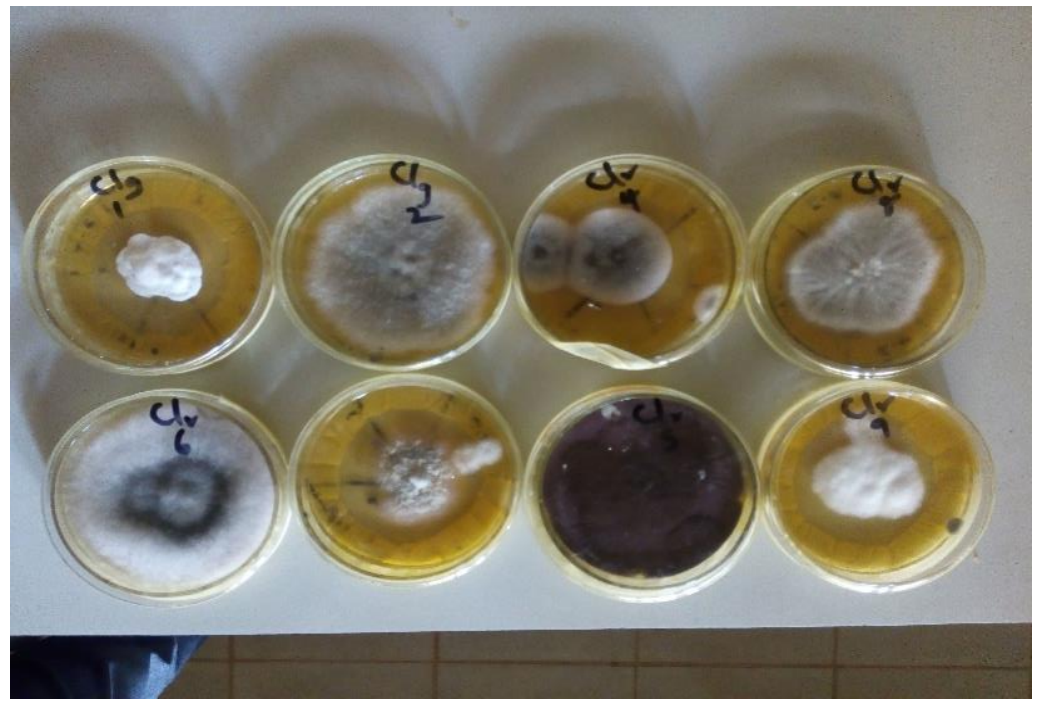

Figure 2 Colony morphology of endophytic fungi isolated from M. utilisima leaves on Malt extract agar

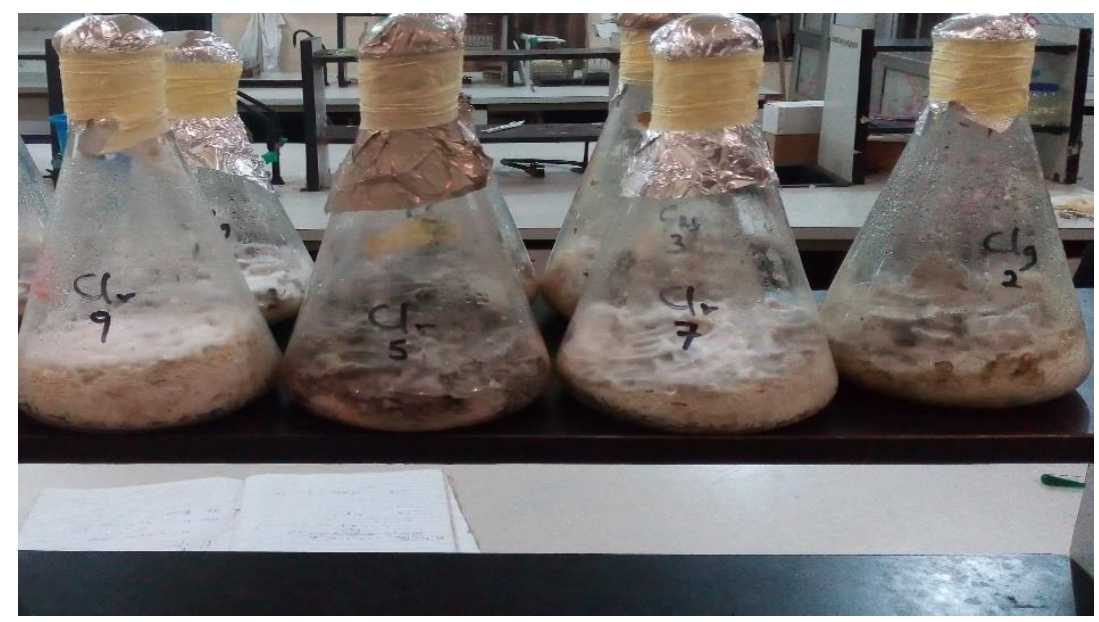

Figure 3 Fermentation of axenic cultures on rice medium 
A total of eight endophytic fungi were isolated from healthy leaves of M. utilisima. Figure 2. Axenic cultures resulting from multiple aseptic sub-culturing were fermented on local rice medium Figure 3 and each fungus fermentation product was extracted using $500 \mathrm{~mL}$ ethylacaetate figure 4.

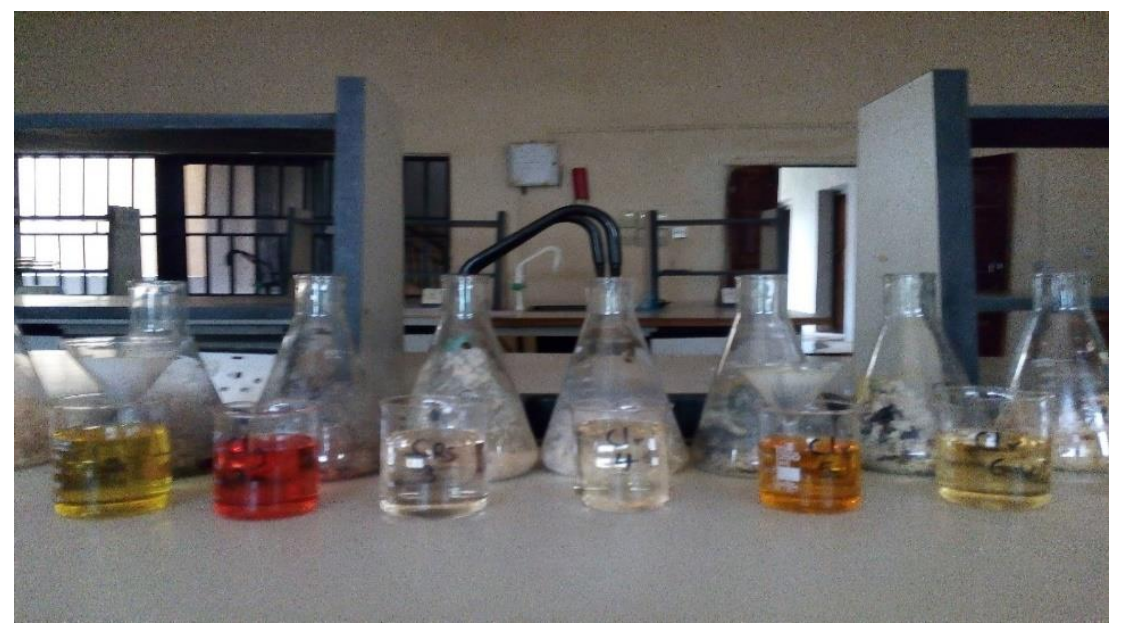

Figure 4 Fermentation filtrate of isolated fungi isolates

\subsection{Antimicrobial activity}

The antimicrobial activity demonstrated by the fungal crude extracts showed a moderate activity when compared with the controls Table 1.

Table 1 Zones of inhibition produced by extracts of endophytic fungi associated with $M$. utilisima against pathogenic organisms.

\begin{tabular}{|c|c|c|c|c|c|}
\hline Isolate code & \multicolumn{5}{|c|}{ Concentration ( 1 mg/mL) / Inhibition Zone Diameter (mm) } \\
\hline & B. subtilis & S. aureus & P. aeruginosa & E. coli & C. albicans \\
\hline Clg1 & 2 & 0 & 0 & 3 & 0 \\
\hline Clg2 & 4 & 0 & 6 & 4 & 0 \\
\hline CRs3 & 4 & 0 & 0 & 2 & 0 \\
\hline Clr4 & 4 & 0 & 5 & 2 & 0 \\
\hline Clr5 & 2 & 0 & 6 & 2 & 0 \\
\hline Clr6 & 4 & 0 & 0 & 4 & 0 \\
\hline Clr7 & 3 & 0 & 0 & 4 & 0 \\
\hline Clr9 & 2 & 0 & 0 & 2 & 0 \\
\hline Cipro 5 $\mu \mathrm{gg} / \mathrm{mL}$ & 17 & 15 & 17 & 19 & - \\
\hline Miconazole $50 \mu \mathrm{g} / \mathrm{mL}$ & - & - & - & - & 22 \\
\hline
\end{tabular}

${ }^{1}$ Antimicrobial potential was indicated by inhibition halos produced around the well and measured in millimeters. Commonly implicated pathogens: B. subtilis, Bacillus subtilis; S. aureus, Staphylococcus aureus; P. aeruginosa, Pseudomonas aeruginosa; E. coli, Escherichia coli; C. albicans, Candida albicans. Each of the fungal crude extract at $1 \mathrm{mg} / \mathrm{mL}$ was assayed against the test organisms. ${ }^{2}$ Ciprofloxacin $5 \mu \mathrm{g} / \mathrm{mL}$ and Miconazole $50 \mu \mathrm{g} / \mathrm{mL}$ were used as the positive controls.

\subsection{Antioxidant activity}

At $1 \mathrm{mg} / \mathrm{mL}, \mathrm{Clg} 2$ and CRs3 produced good radical scavenging activity with an inhibition of 58 and $60 \%$ respectively. DPPH radical scavenging potential was observed by a change in the purple color of DPPH to orange. 
Table 2 Antioxidant activities of fungal crude extracts

\begin{tabular}{|l|l|l|}
\hline Isolate code & Absorbance $\mathbf{5 1 7} \mathbf{~ n m})$ & \% Inhibition \\
\hline Clg1 & 0.938 & 26 \\
\hline Clg2 & 0.583 & 58 \\
\hline CRs3 & 0.565 & 60 \\
\hline Clr4 & 0.78 & 40 \\
\hline Clr5 & 0.988 & 22 \\
\hline Clr6 & 0.958 & 24 \\
\hline Clr7 & 1.054 & 16 \\
\hline Clr9 & 1.035 & 17 \\
\hline Quercitine & 0.077 & 93 \\
\hline DPPH & 1.108 & - \\
\hline
\end{tabular}

Key: C= Endophytic fungal extract from Cassava Leaf; Quercitine $1 \mathrm{mg} / \mathrm{mL}$ was used as the [positive control].

\subsection{Detection of fungal Secondary Metabolites}

Table 3 Bioactive compounds produced by the endophytic fungi isolates

\begin{tabular}{|c|c|c|c|}
\hline $\begin{array}{l}\text { Compound class / } \\
\text { compound name }\end{array}$ & $\begin{array}{l}\text { Retention time } \\
\text { (min) }\end{array}$ & Isolate code & $\begin{array}{l}\text { Reported biological activity / } \\
\text { Reference }\end{array}$ \\
\hline \multicolumn{4}{|l|}{ Alkaloids } \\
\hline \multirow[t]{5}{*}{ Septicine } & 2.0 & $\operatorname{Clg} 1$ & \multirow{5}{*}{$\begin{array}{l}\text { Antibacterial, [9]; Anti-inflammatory, [10]; } \\
\text { Cytotoxicity, [11] }\end{array}$} \\
\hline & 57.24 & $C \lg 2$ & \\
\hline & & Clr5 & \\
\hline & & Clr6 & \\
\hline & & CRs3 & \\
\hline \multicolumn{4}{|l|}{ Peptides } \\
\hline \multirow[t]{2}{*}{ Cyclo(prolylvalyl) } & 16.38 & Clg1 & \multirow{2}{*}{$\begin{array}{l}\text { Antibacterial [12], antioxidant, radical } \\
\text { scavenging, [13] }\end{array}$} \\
\hline & 6.30 & Cr3 & \\
\hline Pentenedioc acid & 23.91 & $C \lg 1$ & $\begin{array}{l}\text { Anticancer, }[14] ; \quad \text { Antioxidant, } \\
\text { inflammatory, [15] }\end{array}$ \\
\hline Neurolenin B & 25.54 & $C \lg 1$ & Antimalarial, [16]; [17] \\
\hline \multicolumn{4}{|l|}{ Naphtha- $\gamma$-pyrone } \\
\hline Rubrofusarin & 33.33 & $C \lg 1$ & $\begin{array}{l}\text { Weak cytotoxicity, [18]; Antibacterial, [19]; } \\
\text { Xanthine oxidase inhibitor, [20] }\end{array}$ \\
\hline \multicolumn{4}{|l|}{ Phenolic acids } \\
\hline p-Hydroxybenzoic acid & 9.86 & $\operatorname{Clg} 2$ & Antimicrobial, [21] \\
\hline Protocatechuic acid & \multirow{2}{*}{\multicolumn{2}{|c|}{$\begin{array}{l}11.61 \text { Clr4 } \\
5.46 \text { Clr6 }\end{array}$}} & \multirow{2}{*}{$\begin{array}{l}\text { Antioxidant [22]; Antimicrobial, Yoswaris et } \\
\text { al., [23] }\end{array}$} \\
\hline & & & \\
\hline
\end{tabular}




\begin{tabular}{|l|l|l|l|}
\hline \multicolumn{2}{|l|}{ Polyketides } & Clg2 & $\begin{array}{l}\text { Inhibitory activity against } \alpha \text {-glucosidase, } \\
\text { [24]; Anticancer, [25] }\end{array}$ \\
\hline Citreoisocoumarin & 24.41 & Clg2 & $\begin{array}{l}\text { Antibacterial; [26]; Antiprotozoal activity, } \\
\text { [27] }\end{array}$ \\
\hline Palitatin & 33.94 & Clr4 & \\
\hline & 32.65 & Clr5 & \\
\hline Pentaketide & 34.23 & Clr6 & Fungistatic and Phototoxic activities, [28] \\
\hline Pestalio pyrone & 28.88 & &
\end{tabular}

A preliminary investigation of the secondary metabolic profiles of the endophytic fungal isolates was carried out. This was done in order to detect the active agents present in the fungal crude extracts that may be responsible for the recorded antibacterial and antioxidant activities. The chemical investigation was achieved using HPLC-DAD system. This provided us data on the chemodiversity of secondary metabolites of endophytic fungi isolated from $M$. utilisima. In our study, ten known compounds of different classes were detected in the fungal fermentation products. These includes Septicine, Cyclo(prolylvalyl), pentenedioc acid, neurolenin B. rubrofusarin, p-hydroxybenzoic acid, citreoisocoumarin, palitantin, protocatechuic acid and petalio pyrone G. Some of these compounds have also been previously isolated from several other fungi and reported to possess various biological activities such as antioxidant and antimicrobial activities amongst others (Table 3; Figure 5-11). The various peaks of the ultraviolet spectrum at each retention time for each compound detected was authenticated by comparing with those available in the database in the library hits of UV spectra data at the Intitut fur Pharmazeutische Biolgie und Biotechnologie, Heinrich-Heine-Universitat, Dusseldorf, Germany.
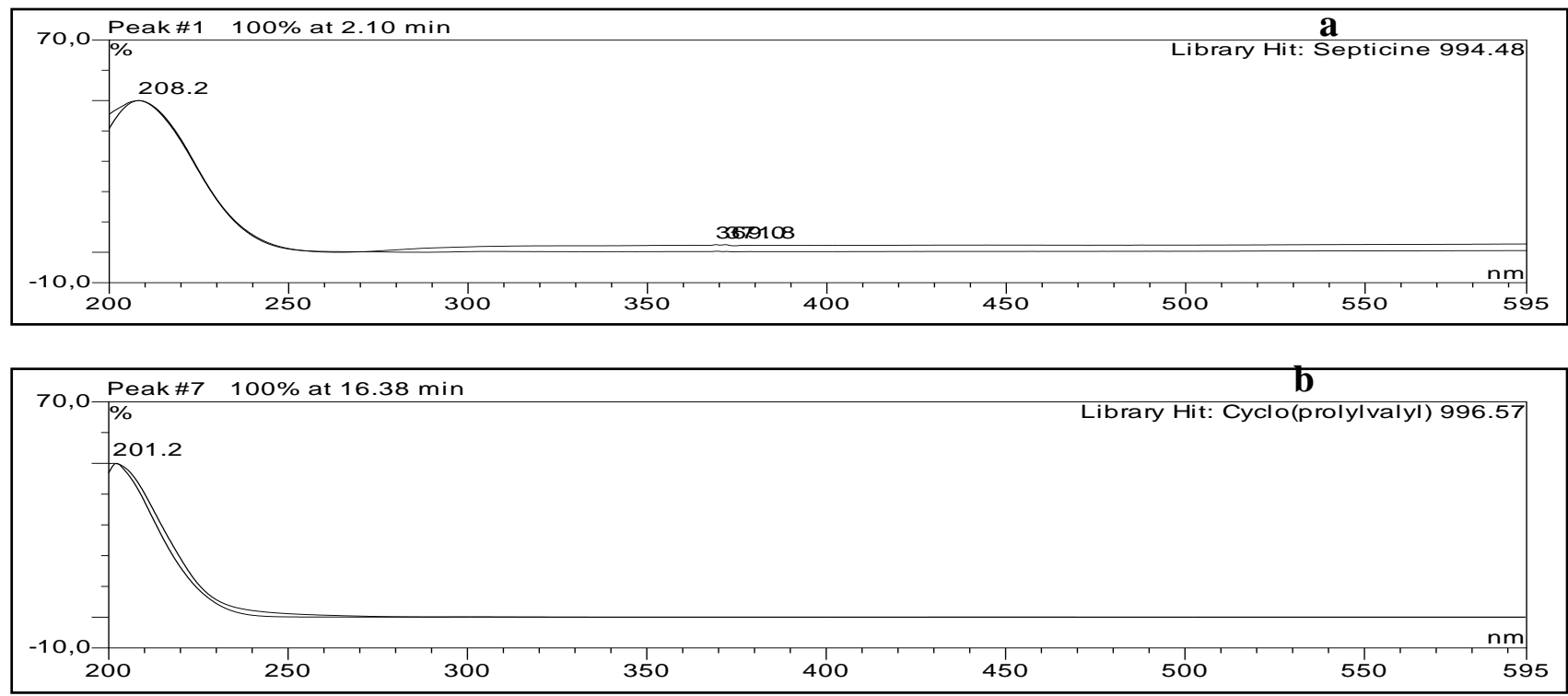

\begin{tabular}{|c|c|c|c|c|c|}
\hline & & C \\
\hline
\end{tabular}



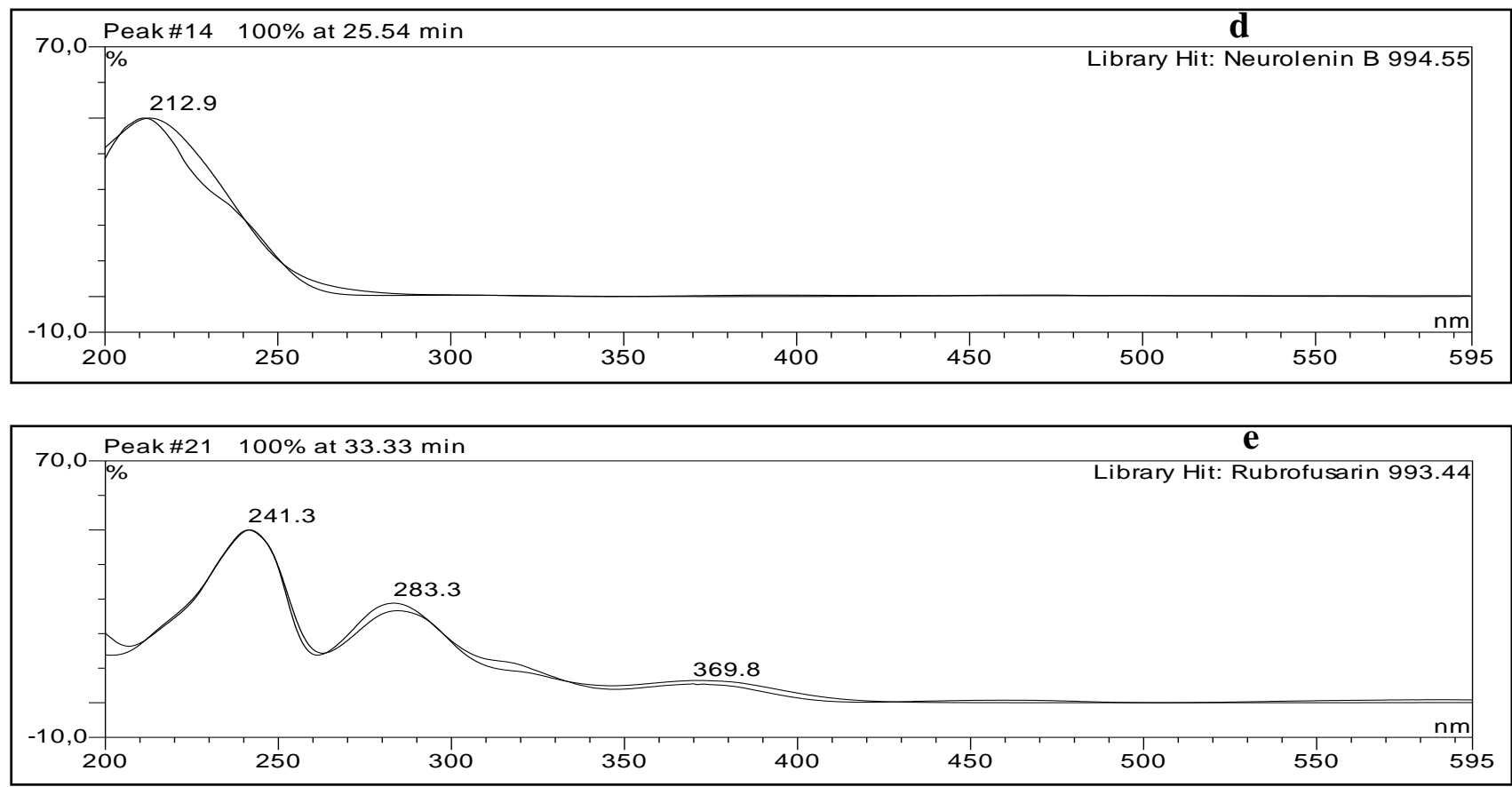

Figure 5 UV spectra of main peaks for Clg1 extract: Library hit of UV spectra of the compound Absorption maximum UV $\lambda$ max (methanol): (a) septicine $208.2 \mathrm{~nm}$; (b) cyclo (prolylvalyl) $201.2 \mathrm{~nm}$; (c) pentenedioc acid $211.1 \mathrm{~nm}$; (d) neurolenin B $212.9 \mathrm{~nm}$ and (e) rubrofusarin 241.33 and $283.3 \mathrm{~nm}$.
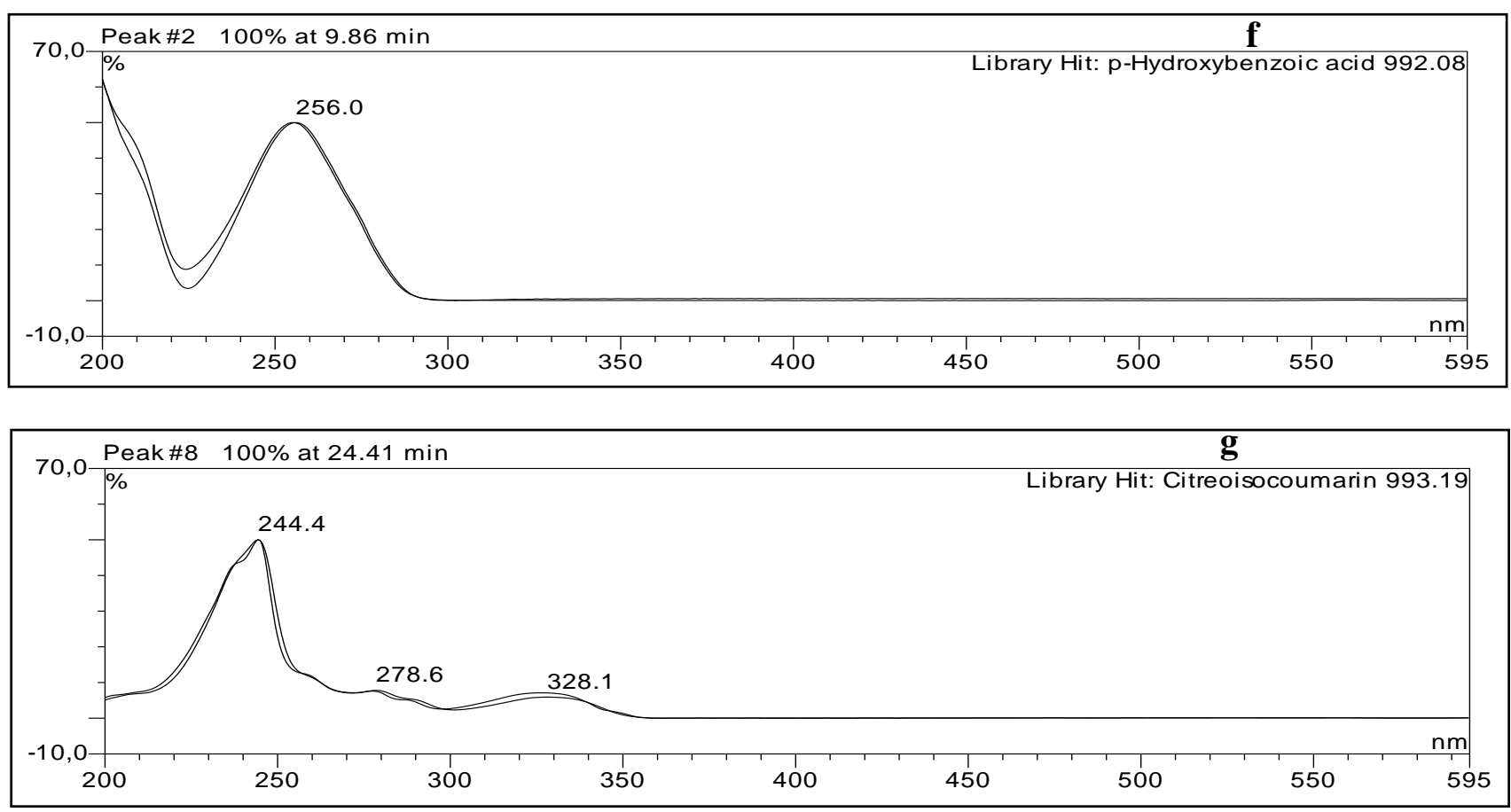

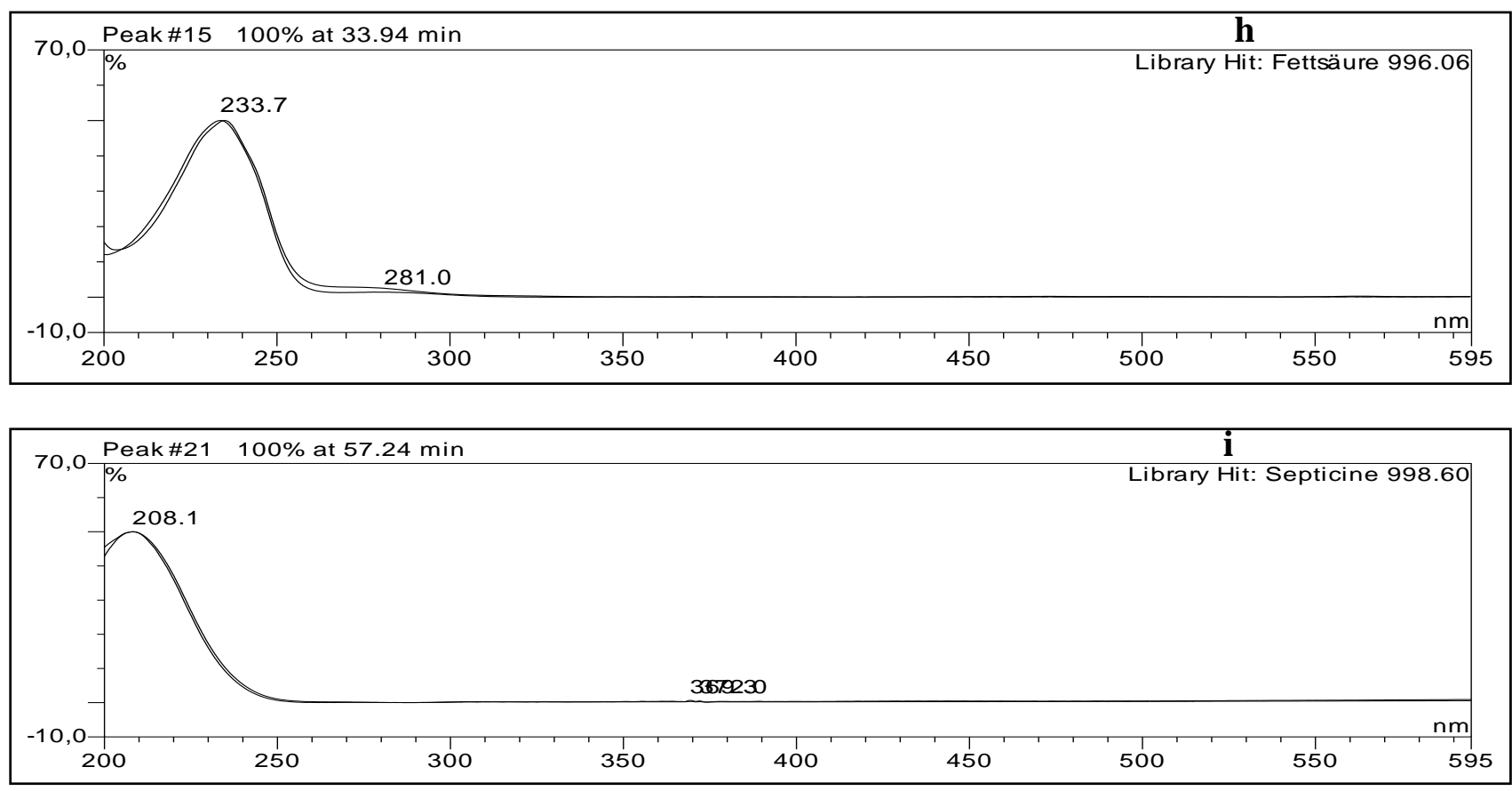

Figure 6 UV spectra of main peaks for Clg2 extract: Library hit of UV spectra of the compound Absorption maximum

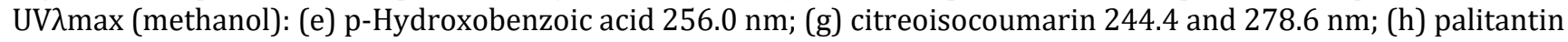
$233.7 \mathrm{~nm}$; and (i) septicine $208.1 \mathrm{~nm}$.
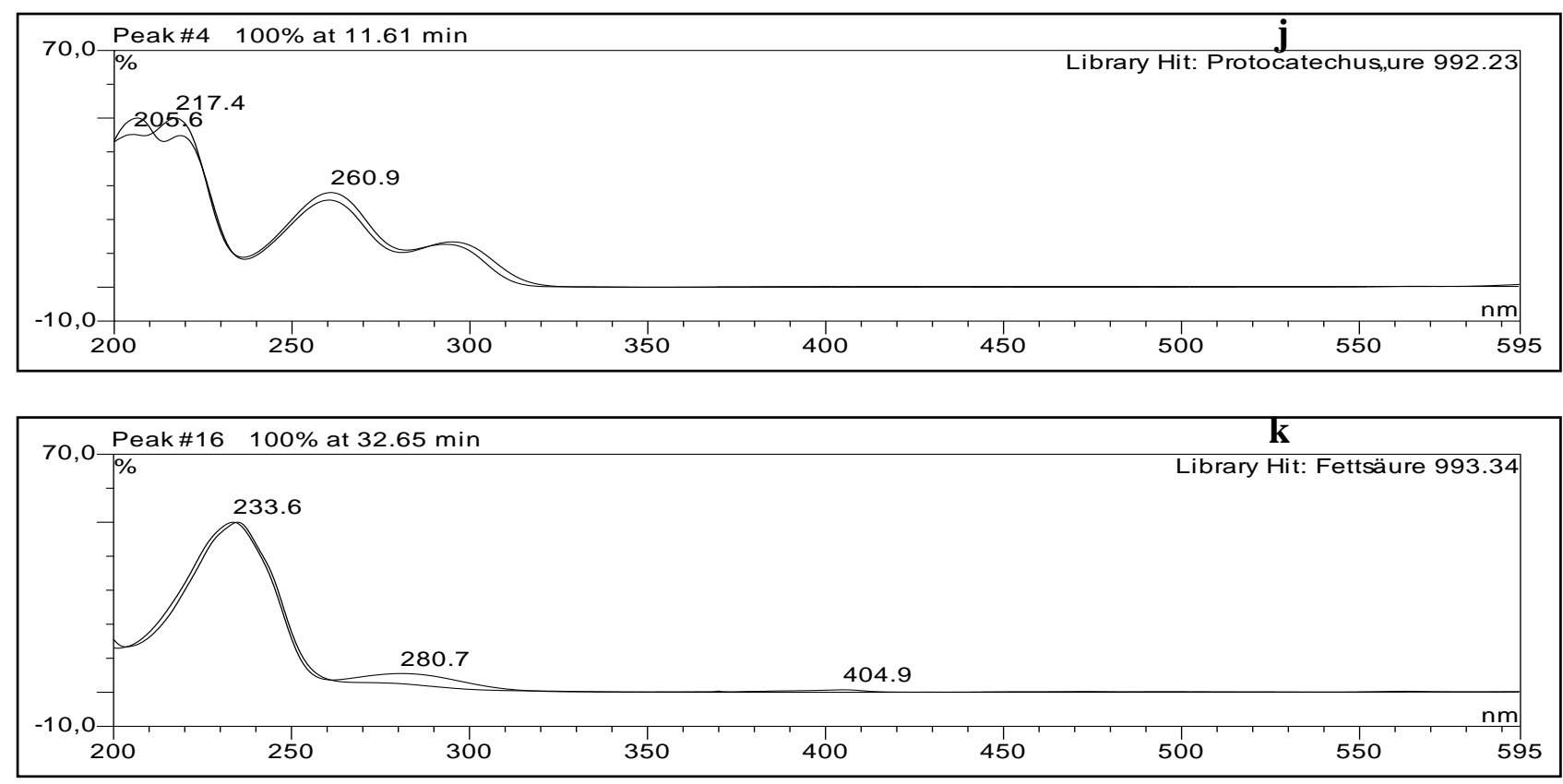

Figure 7 UV spectra of main peaks for Clr4 extract: Library hit of UV spectra of the compound Absorption maximum UV $\lambda \max$ (methanol): (j) protocatechuic acid 205.6, 217.4 and $260.9 \mathrm{~nm}$; and (k) palitantin 233.6. 

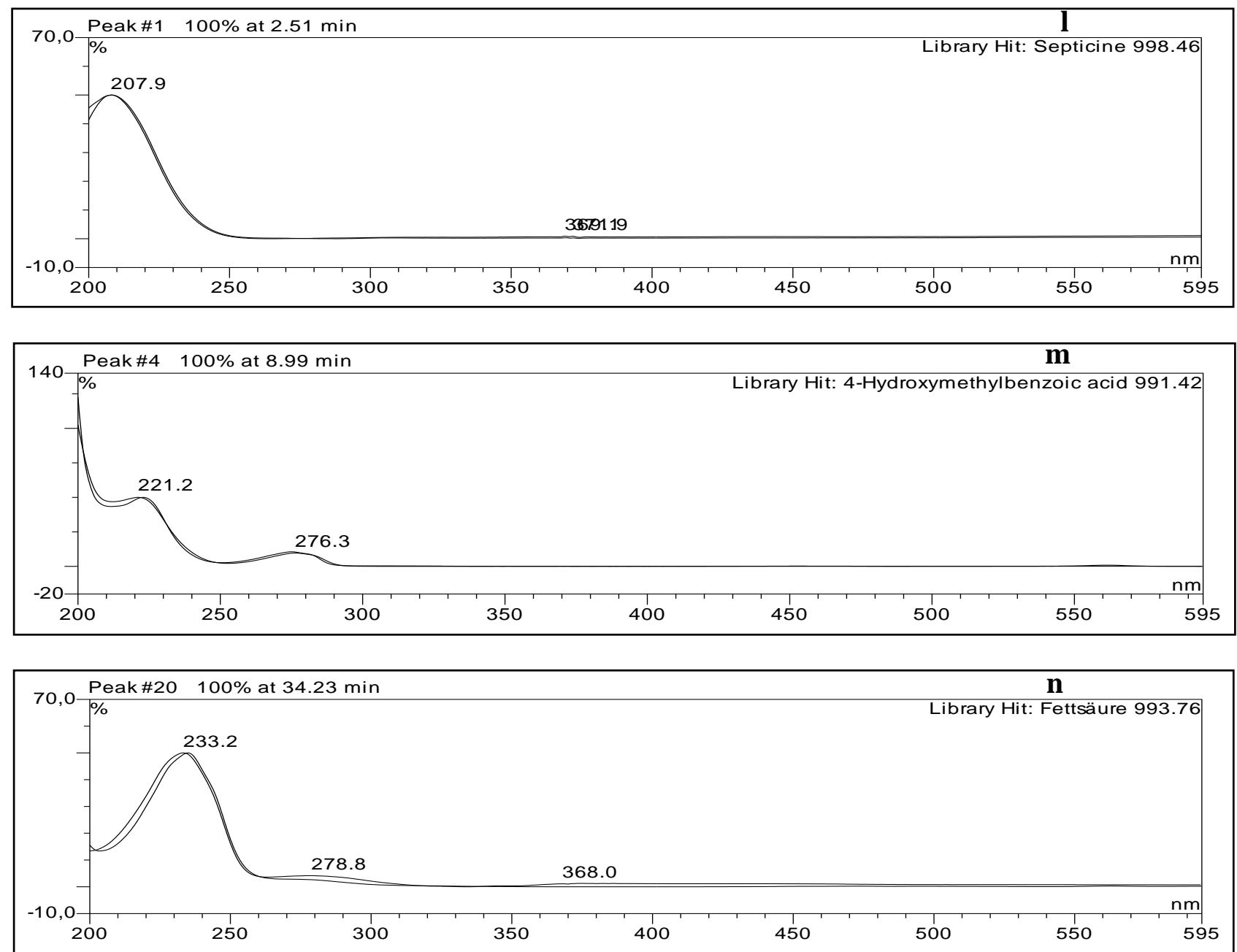

Figure 8 UV spectra of main peaks for Clrs5 extract: Library hit of UV spectra of the compound Absorption maximum UV $\lambda \max$ (methanol): (l) septicine $207.9 \mathrm{~nm}$; (m) 4-Hydroxymethylbenzoic acid $221.2 \mathrm{~nm}$ and $276.3 \mathrm{~nm}$; and (n) palitantin $233.2 \mathrm{~nm}$.
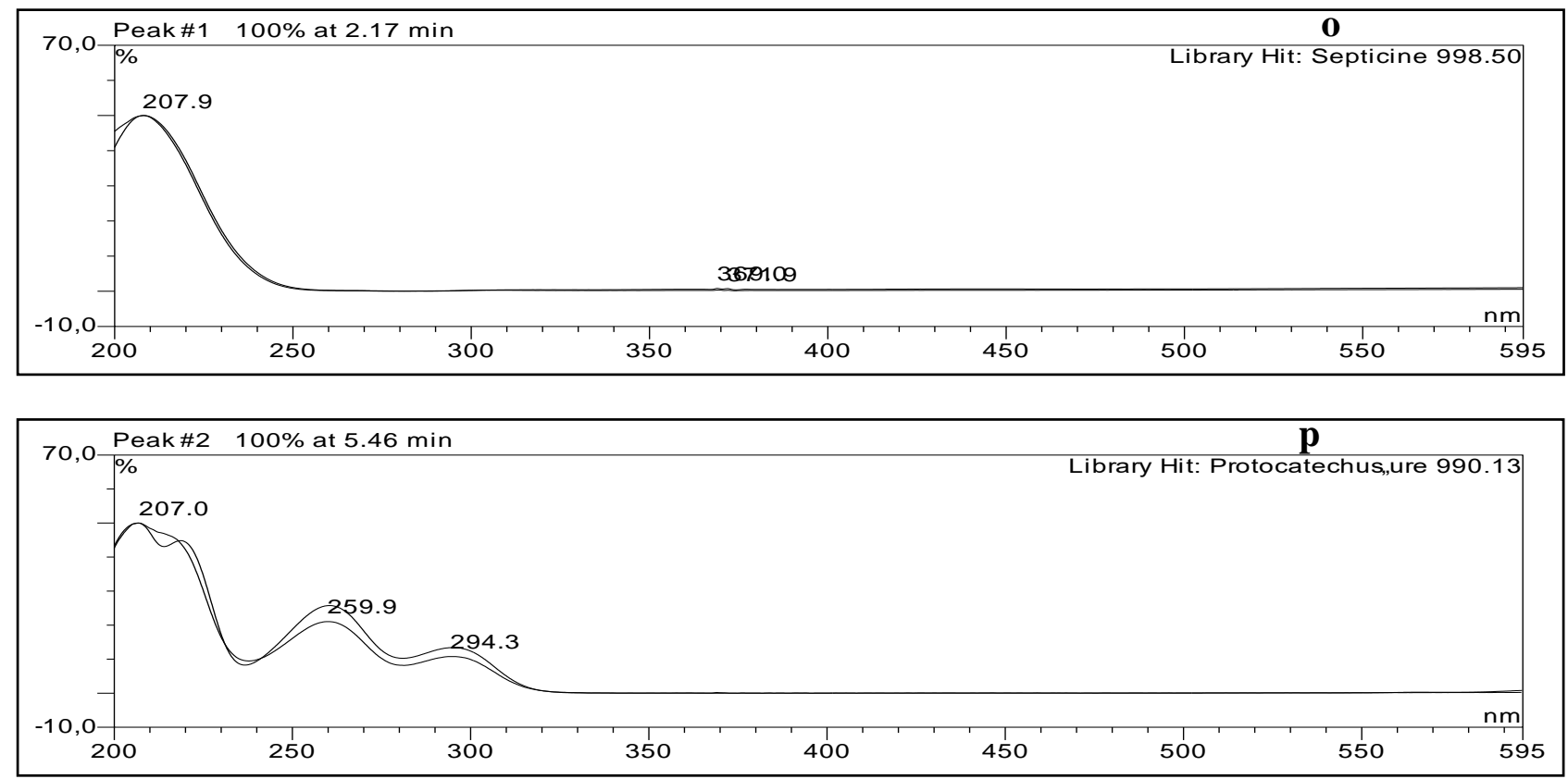


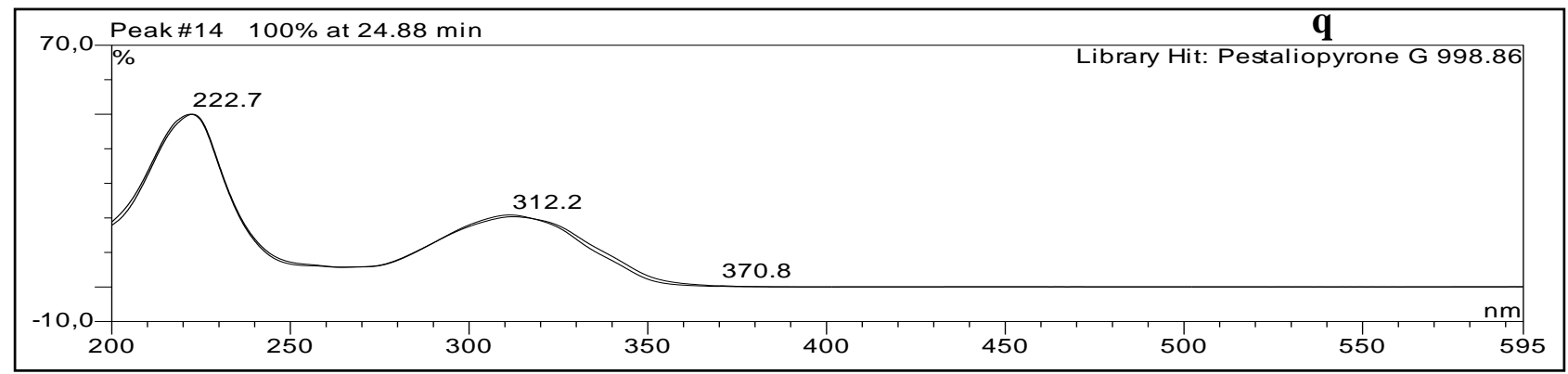

Figure 9 UV spectra of main peaks for Clr6 extract: Library hit of UV spectra of the compound Absorption maximum UV $\lambda \max$ (methanol): (o) septicine $207.9 \mathrm{~nm}$; (p) protocatechuic acid $207.0 \mathrm{~nm}, 259.9 \mathrm{~nm}$ and $294.3 \mathrm{~nm}$, and (q) pestalio pyrone G 222.7 and $312.2 \mathrm{~nm}$.
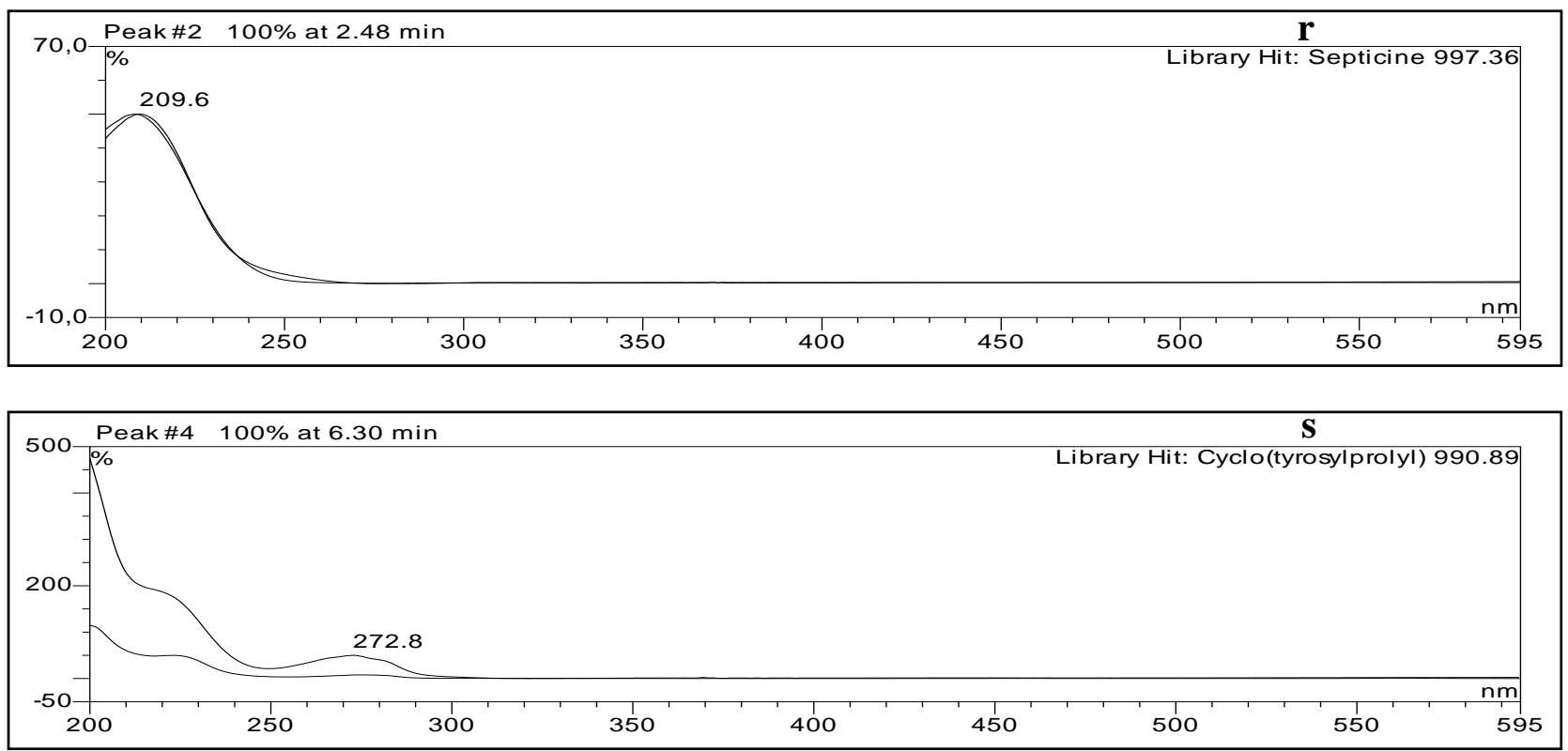

Figure 10 UV spectra of main peaks for CRs3 extract: Library hit of UV spectra of the compound Absorption maximum UV $\lambda$ max (methanol): (r) septicine $209.6 \mathrm{~nm}$ and (s) cyclo(tyrosylprolyl) $272.8 \mathrm{~nm}$. 
<smiles>COc1ccc(C2=C(c3ccc(OC)c(OC)c3)CN3CCC[C@H]3C2)cc1OC</smiles>

Septicine. Chemical formula: $\mathrm{C}_{24} \mathrm{H}_{29} \mathrm{NO}_{4}$<smiles>CCCCC(=O)O</smiles>

Pentedioc acid. Chemical formula: $\mathrm{C}_{5} \mathrm{H}_{10} \mathrm{O}_{2}$<smiles>COc1cc(O)c2c(O)c3c(=O)cc(C)oc3cc2c1</smiles>

Rubrofusarin. Chemical formula: $\mathrm{C}_{15} \mathrm{H}_{12} \mathrm{O}_{5}$<smiles>O=C(O)c1ccc(O)c(O)c1</smiles>

Protocatechuic acid. Chemical formula: $\mathrm{C}_{7} \mathrm{H}_{6} \mathrm{O}_{4}$

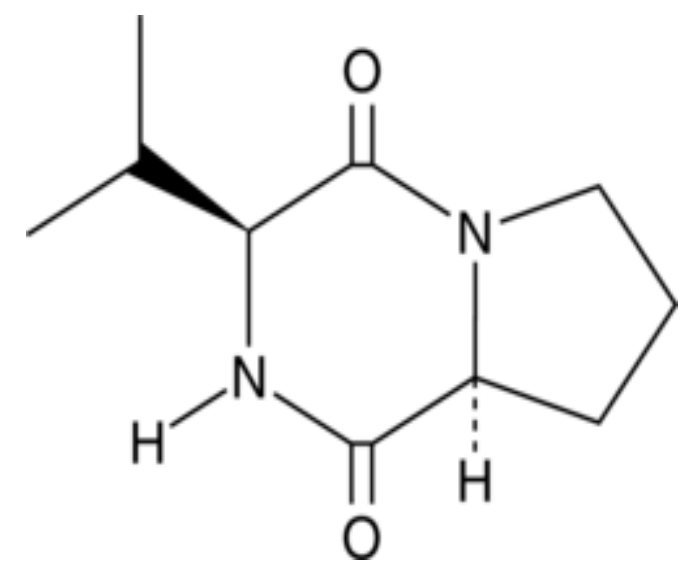

Cyclo (prolylvalyl). Chemical formula: $\mathrm{C}_{10} \mathrm{H}_{16} \mathrm{~N}_{2} \mathrm{O}_{2}$

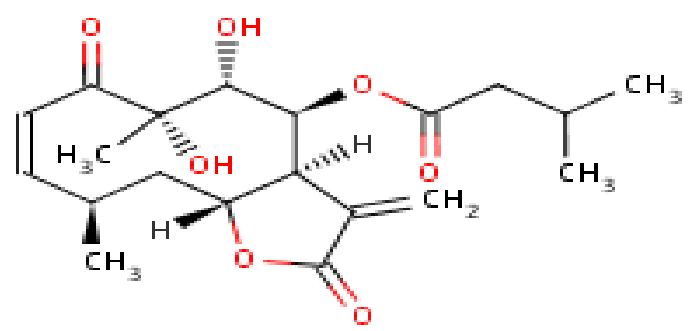

Neurolenin B. Chemical formula: $\mathrm{C}_{22} \mathrm{H}_{30} \mathrm{O}_{8}$

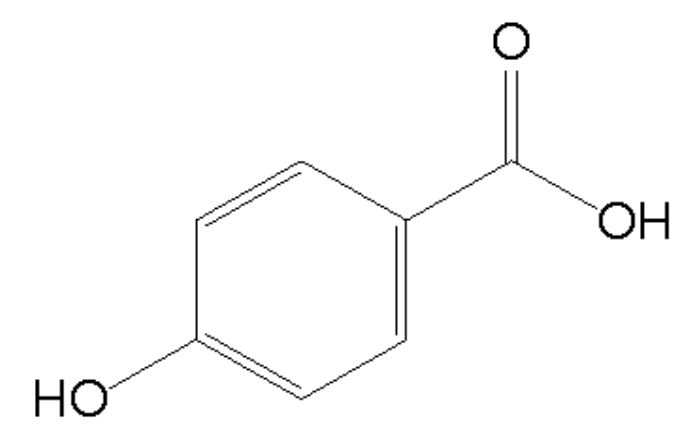

p-Hydroxybenzoic acid. Chemical formula: $\mathrm{C}_{7} \mathrm{H}_{6} \mathrm{O}_{3}$<smiles>CC(=O)C[C@H](O)Cc1cc2cc(O)cc(O)c2c(=O)o1</smiles>

Citreoisocoumarin. Chemical formula: $\mathrm{C}_{14} \mathrm{H}_{14} \mathrm{O}_{6}$ 
<smiles>CCC/C=C/C=C/C1CC(O)C(O)C(=O)C1CO</smiles>

Palitantin. Chemical formula: $\mathrm{C}_{14} \mathrm{H}_{22} \mathrm{O}_{4}$

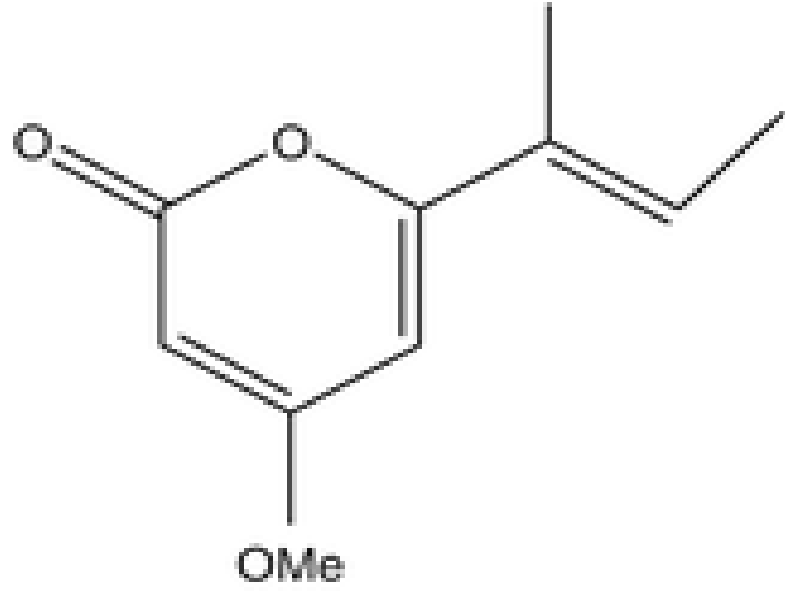

Pestalopyrone

Pestalopyrone. Chemical formula: $\mathrm{C}_{10} \mathrm{H}_{12} \mathrm{O}_{3}$

Figure 11 Chemical Structures of detected compounds

\section{Discussion}

In this study, the diversity of endophytic fungi as well as its secondary metabolites were investigated. A total of eight endophytic fungi were isolated from healthy leaves of $M$. utilisima. The different cultural characteristics of each fungus on malt extract agar highlights the diversity of fungal endophytes associated with the plant under study. Similarly, Li et al., [29] reported the isolation of several endophytic fungi from different cassava cultivars.

The chemical analysis and bioassay of the secondary metabolite produced by each fungus after 21 days of fermentation on rice medium were evaluated. Amongst the fungal extracts tested, three extracts (Clg2, Clr4 and Clr5) showed good antibacterial activity against $B$, subtilis, P. aeruginosa and E. coli. Moreover, all the extracts demonstrated antimicrobial activity against at least one of the test isolates at the tested concentration of $1 \mathrm{mg} / \mathrm{mL}$. The activities of the endophytic fungal extracts against the different test organisms varied. This is evident by the varying inhibition zones produced which ranged between $2-4 \mathrm{~mm}$ (B. subtilis), $5-6 \mathrm{~mm}$ ( $P$. aeruginosa) and $2-4 \mathrm{~mm}$ (E. coli). However, none of the fungal extracts had activity against $S$. aureus and $C$. albicans at the tested concentration. The activities demonstrated by Clg1, Clg2, CRs3, Clr5, Clr6, Clr7 and Clr9 were observed to be broad spectrum with the Gram negatives being the most inhibited (i.e. sensitive) group among the test organisms used in this work. The sensitivity to the fungal extracts by the Gram negatives in comparison with the Gram positives may be attributed to the difference in their cell wall constituents. Also, the broad spectrum activities demonstrated by the active fungal extracts can be attributed to the combined activities of the bioactive constituents present in each extract. Also, this may be due to the differences in the structural details of detected metabolites, in addition to their hydrophilic nature. Indeed, the external membrane of Gram negative and Gram positive bacteria renders their surfaces highly hydrophilic thus are susceptible to hydrophilic compounds. Most of the compounds detected in the fungal extracts produced by the isolates in this work are hydrophilic including the phenolic and polyketide compounds.

The antioxidant assay revealed $C l r 3$ and $C l g 2$ extracts to have good radical scavenging potentials. At $1 \mathrm{mg} / \mathrm{mL}, \mathrm{Clr} 3 \mathrm{and}$ Clg2 demonstrated good radical scavenging activities with a percentage inhibition of 60 and $58 \%$ respectively, comparable to the control quercitine $93 \%$ (positive control).

Going by the recorded antibacterial and antioxidant activities, the endophytic fungi isolated in this work exhibited potential as sources of bioactive agents needed for the development of new medicines thus, it was necessary to assess the chemodiversity of each fungal extract. Therefore, a preliminary investigation of the secondary metabolic profiles of all the endophytic fungi isolated in this study using HPLC-DAD system was determined according to the clear peaks detected in the chromatograms with specific retention indexes (RI) [Table 3: Figure 5 - 11]. The compounds detected suggests a chemodiversity of secondary metabolites evident by their different structural details (classes). These compounds have also been previously isolated from both fungi and plant extract by several authors and reported to possess various biological activities including antioxidant and antimicrobial activities amongst others (Table 3). 
Neurolenin B, a natural product isolated from the Central American plant Neurolaena lobate exhibited antimalarial activity against lymphatic filariasis. Neurolenin B was observed to be the bioactive component responsible for the recorded activity $[16 ; 17]$.

Chemical investigation on the fermentation product of Nectria sp. HN001 showed the presence of citreoisocoumarin present. This compound demonstrated Inhibitory activity on $\alpha$-glucosidase [24]

4-Hydroxy-benzoic acid a phenolic compound was isolated from the extract of Gliocladium roseum CGMCC 3.3657 [30]. Also, this compound was previously detected in a fungal crude extract that showed antimicrobial activity [21]

Pestalopyrone was isolated from the culture filtrates of Pestalotiopsis guepinii. This compound demonstrated phytotoxic activities when applied on some plants as well as antifungal activity [28].

Aspergillus niger isolated from Cynodon dactylon produced Rubofusarium B a compound that exhibited cytotoxic and xanthine oxidase inhibition [20].

Cyclo (polylvaly) a secondary metabolite produced by Streptomyces sp. strain 22-4 showed activity against phytopathogenic bacteria [12].

Pentedioc acid isolated from the leaf extract of Bougainvillea x buttiana (var. Rose) Holttum and Standl extract (BxbREE) showed antioxidant and anti-inflammatory activities when evaluated [15]; also a derivative of pentanedioic acid amide Synthesized was observed to possess antineoplastic activity In vitro and in vivo [14].

In a study conducted by Fuska et al., [27], palitantin isolated from a submerged culture of Penicillium frequentans 60A/7 demonstrated antiprotozoal activity against Leishmania brasilliensis. Also, palitantin was isolated from the extract of an enophytic fungus Aspergillus fumigatiaffnis and observed to inhibit the growth of Enterococcus faecalis UW 2689 and Streptococcus pnuemoniea [26].

Finally, Protocatechuic acid (PCA) a highly reactive phenolic compound has been detected in several plant extracts. Several reports indicates PCA to be biologically active with potentials as antimicrobial and antioxidant agents etc. [23]. Similarly, in another study carried out by Nguyen et al., [31] on the inhibitory activity of Protocatechuic acid isolated from extract of Paenibacillus elgii HOA73, PCA displayed potent antifungal activity against the selected fungi isolates.

\section{Conclusion}

In conclusion, in this study we isolated different endophytic fungi from healthy leaves of Manihot utilisima. The varieties of fungal endophytes isolated in this work was based on their diverse morphological (cultural) features observed on Malt extract agar. Also, with the aid of a standard chemical (HPLC) analytic protocol, several classes of bioactive secondary metabolites with varying biological activities were detected in the fermentation product of each fungus. Thus, our study provides additional useful data on the reliability of fungal endophytes from Manihot utilisima for production of important natural bioactive metabolites with pharmaceutical applications.

\section{Compliance with ethical standards}

\section{Acknowledgments}

The authors are grateful to Prof. Dr. Peter Proksch of the Intitut fur Pharmazeutische Biolgie und Biotechnologie, Heinrich-Heine-Universitat, Dusseldorf, Germany.

\section{Disclosure of conflict of interest}

The authors declare no conflict of interest.

\section{References}

[1] Strobel GA, Daisy B, Castillo U, Harper J. Natural Products from Endophytic microorganisms. J. Nat. Prod. 2004; $67: 257$ 
[2] Food and Agriculture Organization of the United Nations. Available from: http://www.fao.org/ag/agp/agpc/gcds. 1990

[3] Bahekar S, Kale R. PHYTOPHARMACOLOGICAL ASPECTS OF MANIHOT ESCULENTA CRANTZ (CASSAVA) - A REVIEW. Mintage journal of pharmaceutical and medicinal sciences. 2013; Vol 2 Issue 1

[4] Yuniarti T. Ensiklopedia tanaman obat tradisional. Yogyakarta: Media Pressindo, Yogyakarta. 2008. Distributor tunggal,

Buku

Kita, $439 \mathrm{p}$

[5] Zakaria Z.A. The in vitro antibacterial activity and brine shrimp toxicity of Manihot esculenta var. Sri Pontian (Euphorbiacea) extracts. Int. J. Pharmacol. 2006; 2(2):216-20.

[6] Yi B, Hu L, Mei W, Zhou K, Wang H, Luo Y, Wei X and Dai H. Antioxidant Phenolic Compounds of Cassava (Manihot esculenta) from Hainan. Molecules. 2011; 16(12): 10157-10167.doi: 10.3390/molecules161210157

[7] Okezie U.M, Eze P.M, Okoye F.B.C, Ikegbunam M.N, Ugwu M.C, Esimone C.O. Secondary Metabolites from an endophytic fungus of Vernonia amygdalina. African Journal of Pharmaceutical Research and Development. 2017; Vol. 9 No.1:pp. 24-26

[8] Okezie UM, Okoli OA, Ajaegbu EE, Okoye FBC, Esimone CO Antioxidant Activities of Extracts of Endophytic Fungi Isolated from Healthy Leaves of Carica Papaya International Journal of Research Studies in Biosciences (IJRSB) 2021; Volume 8, Issue 8:PP 48-56 ISSN No. (Online) 2349-0365 DOI: https://doi.org/10.20431/23490365.0808005

[9] Ibtisamatul Aminah, Andani E. Putra, Dayar Arbain, Dian Handayani. Antibacterial potential of fungi derived extracts of marine sponge Acanthostrongylophora ingens. AACL Bioflux. 2020: Volume 13, Issue 2. http://www.bioflux.com.ro/aacl

[10] Lee D S, Jang J H, Ko W, Kim K S, Sohn J, Kang M S, Ahn J S, Kim Y C, Oh H. PTP1B inhibitory and anti-inflammatory effects of secondary metabolites isolated from the marine-derived fungus Penicillium sp. JF-55. Marine Drugs $2013 ; 11(4): 1409-1426$.

[11] Rusman Y. Isolation of new secondary metabolites from sponge-associated and plant-derived fungi. PhD Thesis, Universität Düsseldorf, Germany. 2006; 291 pp

[12] Pakorn Wattana-Amorn, Waranya Charoenwongsa, Christopher Williams, Matthew P Crump, Busaya Apichaisataienchote. Antibacterial activity of cyclo(L-Pro-L-Tyr) and cyclo(D-Pro-L-Tyr) from Streptomyces sp. strain 22-4 against phytopathogenic bacteria. Epub 2016; 30(17):1980-3. DOI: 10.1080/14786419.2015.1095747

[13] Wang X, Li Y, Zhang X, Lai D And Zhou L. Structural Diversity and Biological Activities of the Cyclodipeptides from Fungi. Molecules. 2017; 22(12):2026; https://doi.org/10.3390/molecules22122026

[14] Dutta S, Ravali SGR, Ray S and Nagarajan K. Synthesis, structural characterization and biological activity of 2-(4 methylbenzenesulphonamido) pentanedioic acid amide derivatives: In vitro and in vivo antineoplastic activity. Bangladesh J Pharmacol; 2015; 10:7-15

[15] Guerrero RV, Abarca-Vargas R, Petricevich V. 2017. Chemical Compounds and Biological activity of an extract from Bougainvillea $x$ buttiana (var. rose) Holttum and Standl. International Journal of Pharmacy and Pharmaceutical Sciences. 2017; Vol 9, Issue 3:ISSN- 0975-1491

[16] Blair S, Mesa J, Correa A, Carmona-Fonseca J, Granados H, Saez J. Antimalarial activity of neurolenin B and derivates of Eupatorium inulaefolium (Asteraceae). Pharmazie 2002; 57(6):413-5.

[17] Kerry L. Barnett, Kevin M. Shea, Catherine McGeough, Kristine Trotta, Steven Williams, Minh Ly, Kathryn Aloisio. Semester-Long Course-Based Research Project in Second-Semester Organic Chemistry: Synthesizing Potential Lead Compounds for the Treatment of a Neglected Tropical Disease. J. Chem. Educ 2020; 97,4:1008-1016

[18] Usami, Y; Aoki, S; Hara, T; Numata, A New dioxopiperazine metabolites from a Fusarium species separated from a marine alga. J Antibiot. 2002; 55:655-659. [CrossRef] [PubMed]

[19] Han P, Zhang X, Xu D, Zhang B, Lai D And Zhou L. Metabolites from Clonostachys Fungi and Their Biological Activities. J. Fungi. 2020; 6(4):229; https://doi.org/10.3390/jof6040229

[20] Song YC, H Li, YH Ye, CY Shan, YM. Yang, RX Tan Endophytic naphthopyrone metabolites are co-inhibitors of xanthine oxidase, SW1116 cell and some microbial growths. FEMS Microbiology Letters. 2004; Volume 241, Issue 1:Pages 67-72, https://doi.org/10.1016/j.femsle.2004.10.005 
[21] Ujam NT; Eze PM Ejikeugwu C Okoye FBC Esimone CO Antimicrobial Activity of Metabolites of Lasiodiplodia theobromae isolated from Psiduim guajava. - International Journal of Innovative Science, Engineering \& Technology, 2020; Vol. 7 Issue 2:ISSN (Online) 2348 - 7968

[22] Xican Li, Xiaozhen Wang, Dongfeng Chen, Shuzhi Chen Antioxidant Activity and Mechanism of Protocatechuic Acid in vitro. Functional Foods in Health and Disease. 2011; 7:232-244 Page 232 of 244 Research Open Access

[23] Yoswaris Semaming, Patchareewan Pannengpetch, Siriporn C. Chattipakorn and Nipon Chattipakorn. Phamacological Properties of Protocatechuic acid and its Potential roles as Complementary Medicine. Hindawi Evidence-Based complementary and Alternative Medicine. 2015. doi: 10.1155/2015/593902.

[24] Cui, H; Liu, YY; Nie, Y; Liu, ZM; Chen, SH; Zhang, ZR; Lu, YJ; He, L; Huang, XS; She, ZG Polyketides from the mangrove-derived endophytic fungus Nectria sp. HN001 and their $\alpha$-glucosidase inhibitory activity. Mar. Drugs. 2016: 14:86

[25] Neelgundmath, M, Dinesh, K R, Mohan, C D, Li, F, Dai, X., Siveen, K S, et al. Novel synthetic coumarins that targets NF-kappaB in Hepatocellular carcinoma. Bioorg. Med. Chem. Lett. 2015; 25:893-897. doi: 10.1016/j.bmcl.2014.12.065

[26] Antonius RB Ola, Bibiana D Tawo, Henderiana LL Belli, Peter Proksch, Dhana Tommy, Euis Holisotan Hakim. A New Antibacterial Plyketide from the Endophytic fungi Aspergillus fumigatiaffinis. Natural Product communications. 2018. DOI: 10.1177/1934578x1801301202

[27] Fuska J, Kuhr I, Fuskova A.The effect of Palitantin, a metabolite of Penicillium frequentans on Leismania brasiliensis. Folia Microbiologica 1970; 15:111-116

[28] Turkkan, M; Andolfi, A; Zonno, MC; Erper, I; Perrone, C; Cimmino, A; Vurro, M. Evidente, A. Phytotoxins produced by Pestalotiopsis guepinii, the causal agent of hazelnut twig blight. Phytopathol. Mediterr. 2011; 50:154-158

[29] Li H, Yan C, Tang Y, Ma X, Chen Y, Chen S, Lin M, Liu Z. Endophytic bacterial and fungal microbiota in different cultivars of cassava (Manihot esculenta Crantz). Journal of Microbiology. 2020; 58:614-623

[30] Yang, C; Meng, Q; Wang, M; Yuan, J; Shi, Z; Zhang, Y; Fu, S. Study on phenolic compounds of secondary metabolites from the fungus Gliocladium roseum CGMCC.3.3657. J. Zunyi Med. Univ. 2018; 41:674-677

[31] Nguyen XH, Naing KW, Lee YS, Moon JH Isolation and characteristics of protocatechuic acid from Paenibacillus elgii HOA73 against Botrytis cinera on strawberry fruits. Journal of Basic Microbiology. 2014; 55(5) 